\title{
Synthesis of Triphenylamine Trisazo Dye and Study of its Uses in Dye Sensitized Solar Cells
}

\author{
G. K. R. Senadeera ${ }^{1, *}$ and K-J. Jiang ${ }^{2}$ \\ ${ }^{1}$ Institute of Fundamental Studies, Kandy 20000, Sri Lanka, \\ ${ }^{2}$ Institute of Chemistry, Chinese Academy of Sciences, Beijing 100080, P.R. China,
}

\begin{abstract}
A new triazo dye was synthesized from tri(p-aminophenyl)amine and 2 hydroxy-3-napthoic acid and explored the possibilities of its uses in dye sensitized solar cells for the first time. The photocells were able to generate reasonably high photocurrent in the presence of the electron donating ionic liquids in the electrolyte composed of redox couple $\mathrm{I}_{3}^{-} / \mathrm{I}^{-}$. Cells fabricated by sensitizing $\mathrm{TiO}_{2}$ generated a short-circuit photocurrent of $\sim 3.5 \mathrm{~mA} \mathrm{~cm}$, an open-circuit photovoltage of $\sim 500 \mathrm{mV}$ with a total power conversion efficiency of $\sim 1 \%$ under simulated full sunlight of $100 \mathrm{~mW} \mathrm{~cm}^{-2}$ (Air Mass 1.5).
\end{abstract}

\section{INTRODUCTION}

With the advent of the highly efficient "Gratzel cell", dye sensitization of wide band gap semiconductors has become a rapidly expanding solar-light conversion system with potential practical applications [1]. In these devices, upon absorption of light, the dye adsorbed on the surface of the semiconductor injects and electron in to the conduction band of the semiconductor. The oxidized dye molecule is then regenerated by accepting an electron from a reducing agent present in the electrolyte of the cell. In this context, the best performing sensitizers were carboxyl group-bearing $\mathrm{Ru}$ complexes such as cis-

\footnotetext{
*Corresponding Author; E-mail: rsena@ifs.ac.lk
} 
dithiocyanatobis $\left(4,4^{\prime}\right.$,-dicarboxy-2-2'bipyridine)ruthenium (II) giving photovoltaic energy conversion efficiencies, as high as $10 \%$ at AM 1.5 standard solar spectrum $(100 \mathrm{~mW}$ $\mathrm{cm}^{-2}$ ). Consequently, there has been increasing interest in studying of these dyes [1-6]. However the high cost of $\mathrm{RuCl}_{3}$ and the difficulties of synthesizing $\mathrm{Ru}$ (II) polypyridine complexes limit the practical application of these cells at the present time. Therefore, some pure organic dyes with rich photopysical properties are expected to be promising sensitizers for nanocrystalline solar cells in view of their character of less cost and easy tailoring. In this context, Azo dyes and pigments have attracted considerable attention in recent times since they represent not only the largest chemical class in the colour index but also the largest class of the dyes used in the industry and the analytical chemistry [11-14]. In addition, they are also widely investigated for xerographic photoreceptor application as charge generation materials. The synthetic pathways for Azo compounds, by the classic azotization and coupling reaction, are relatively simple [11]. In this communication we report for the first time synthesis of a new triazo dye from tri(p-aminophenyl) amine and 2hydroxy - 3- napthoic acid and explored the possibilities of use in photovoltaic devices (PVD).

\section{EXPERIMENTAL}

\subsection{Synthesis of dye}

Scheme 1 shows the synthetic procedures of the triazo dye. Tri(4-nitrophenyl)amine (3 mmol) (Aldrich) and $6 \mathrm{M} \mathrm{HCl}(30 \mathrm{ml})$ were mixed in a $100 \mathrm{ml}$ three neck flask equipped with a mechanical stir and refluxed for 24 hours. Zinc powder (1g) was added slowly to the reaction vessel and refluxing was continued for another one hour. The solution was then cooled down to room temperature and filtered. The filtrate was then diluted with water, adjusted to $\mathrm{pH}=12$ and extracted with $\mathrm{CH}_{2} \mathrm{Cl}_{2}$. The solvent was removed in vacuum to give a purple solid. The resulting tris(4- aminophenyl) amine was stirred in $18 \% \mathrm{HCl}$, for 1 hour and cooled down to $0-5{ }^{\circ} \mathrm{C}$. Then $\mathrm{NaNO}_{2}$ was added drop wise while keeping the solution at $0-5{ }^{\circ} \mathrm{C}$ and filtered the solution. The solution was then precipitated by adding fluoroboric acid, $(0.1 \mathrm{M})$ and collected by filtration. The resulting tetrazolium salt was dissolved in DMF at $0-5{ }^{\circ} \mathrm{C}$ and a solution of 2-hydroxy-3-napthoic acid in DMF was added. The solution $\mathrm{pH}$ was then adjusted to 11 by adding aqueous solution of $\mathrm{NaOH}$ 
slowly. After the addition was completed, the solution was stirred at room temperature for $4 \mathrm{~h}$ and then diluted with distilled water. Then the $\mathrm{pH}$ of the solution was adjusted to 4 by adding $10 \% \mathrm{HCl}$. The precipitated crude powder was filtered off, isolated by filtration, washed with water and recrysterlized from ethanol and dried under vacuum, giving purple solid product Triphenylamine trisazo (TPTA) dye (yield: 41\%). Formation of TPTA was confirmed by ${ }^{1} \mathrm{H}$ NMR (JEOL EX-270, $270 \mathrm{MHz}$ ).

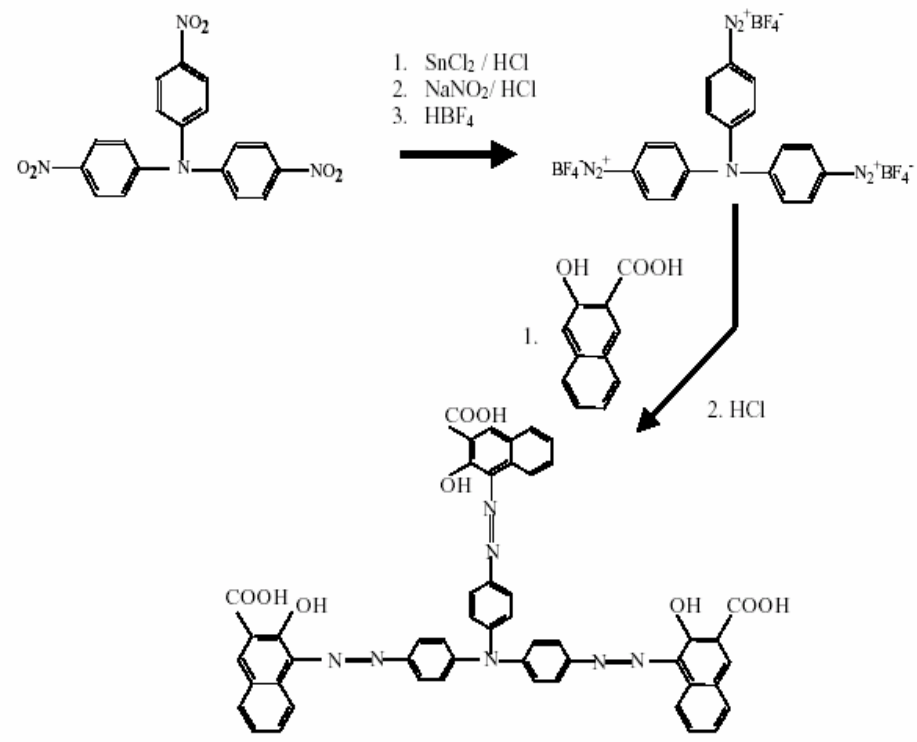

Scheme 1: Synthesis of TPTA

\subsection{Fabrication of solar devices}

In the fabrication of dye sensitized solar devices (DSCs) containing semiconducting nanocrystalline $\mathrm{TiO}_{2}$ films with various thickness, the $\mathrm{TiO}_{2}$ paste purchased from "Solaronix" (Solaronix Nanooxide T, Switzerland) was coated by the "doctor blade" method on pre-cleaned fluorine doped conducting tin oxide (FTO) glasses (Nippon Sheet glass, $10-12 \mathrm{Ohm} \mathrm{sq}^{-1}$ ) and sintered at $500{ }^{\circ} \mathrm{C}$ for 1 hour. The thickness of the films on FTO substrates were determined by a Dektak profilometer (Veeco, Dektack 3).

The dye TPТA $\left(5 \times 10^{-4} \mathrm{~mol}^{-1}\right)$ was then dissolved in dried dimethyl sulfoxide (DMSO) and the above semiconducting films were dipped in the dye solution for $60 \mathrm{~min}$ at $80{ }^{\circ} \mathrm{C}$. After the dye adsorption films were washed with dried ethanol and dried under $\mathrm{N}_{2}$. DSCs were constructed by introducing the redox electrolyte consisting of 1-methyl 3-n- 
hexylimidazolium iodide (HMImI) $(0.5 \mathrm{M}), \mathrm{I}_{2}(0.05 \mathrm{M}), 0.40 \mathrm{M}$ LiI and $(0.5 \mathrm{M})$ tertbutylpyridine in a mixture of actonitrile and ethylene carbonate $(6: 4 \mathrm{v} / \mathrm{v})$ between the TPTA coated electrodes and a Pt coated counter electrode as shown in the Figure 1. Photoenergy conversion efficiency was evaluated using standard solar irradiation of $100 \mathrm{~mW}$ $\mathrm{cm}^{-2}$ (AM1.5) with a solar simulator (YSS-50A, Yamashita Denso) and a computer controlled voltage current sourcemeter (R6246, Advantest) at $25^{\circ} \mathrm{C}$. The dependence of the short-circuit photocurrent on the incident light intensity was examined by controlling the intensity using an optical lens and neutral density filters. The effectiveness of a cell to convert light of various wavelengths into electrical current was measured as the incident photon to current conversion efficiency (IPCE) defined as the number of electrons generated by light per number of photons incident on the cell as formulated by IPCE $\%=$ $1240 \mathrm{~J}_{\mathrm{sc}} / \lambda \mathrm{W}_{\mathrm{i}}$, where $\mathrm{J}_{\mathrm{sc}}$ is the short circuit current density $\left(\mu \mathrm{A} \mathrm{cm}^{-2}\right), \lambda$, the excitation wavelength $(\mathrm{nm})$ and $\mathrm{W}_{\mathrm{i}}$, is the photon flux $\left(\mathrm{W} \mathrm{m}^{-2}\right)^{12}$ using a commercial setup for IPCE measurement (PV-25DYE, JASCO). All measured IPCE values were not corrected for the loss of incident light due to the absorption and reflection by the conducting glass support. The optical absorption spectrum of TPTA in DMSO was measured with JASCO (V-570) UV-Visible spectrophotometer. The oxidation potential of the polymer in DMSO was measured in a standard-three-electrode-one-compartment cell using $\mathrm{Ag} / \mathrm{AgCl}$ in saturated $\mathrm{KCl}$ solution, $\mathrm{Pt}$ and glassy carbon electrodes as reference, counter and working electrodes respectively.

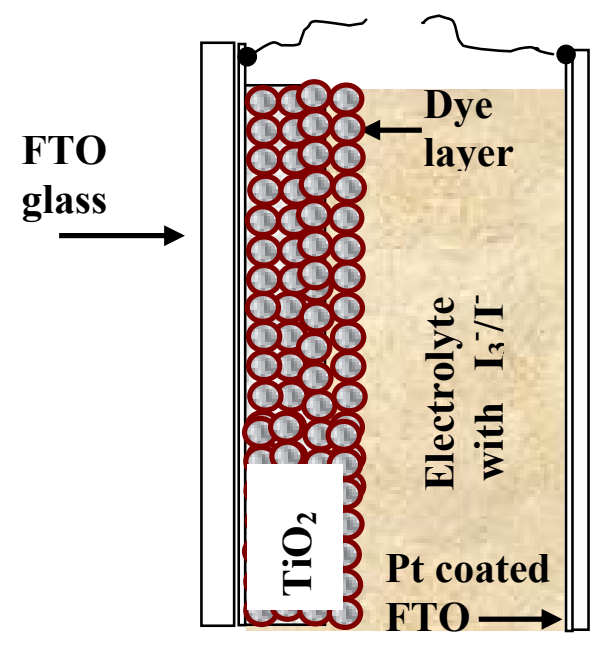

Figure 1: Schematic diagram of construction of photcells with TPTA and $\mathrm{I}_{3}^{-} / \mathrm{I}^{-}$electrolyte. 


\section{RESULTS AND DISCUSSION}

The UV-vis absorption spectrum of TPTA dye in DMF and absorbed on a $\mathrm{TiO}_{2}$ film $(2.3$ um Thick) are shown in figure 2 (a) and (b) respectively. In DMF solution (curve (a)), the dye shows a peak at $520 \mathrm{~nm}$ (absorptivity $=9.5 \times 10^{4} 1 \mathrm{~mol}^{-1} \mathrm{~cm}^{-1}$ ) and a shoulder peak around $545 \mathrm{~nm}$. The threshold wavelength of the spectrum is around $620 \mathrm{~nm}$, which is desirable for the light harvesting of corresponding dye sensitized solar cells. When each dye molecule was anchored on $\mathrm{TiO}_{2}$ film via three carboxylic acid groups, the absorption band became broaden and the peak is blue shifted, indicating that the dye on the $\mathrm{TiO}_{2}$ film degraded under illumination. It is observed that the colour of the dye on $\mathrm{TiO}_{2}$ film turned from red to yellow under illumination in the absence of electrolyte. Generally it is proved that excited state of azo dyes can inject electrons to $\mathrm{TiO}_{2}$ particles within a few Pico seconds to form the oxidation state [11,12], which can be degraded to give corresponding aromatic amines in the absence of donors such as $\mathrm{I}^{-} / \mathrm{I}_{3}{ }^{-}$in a electrolyte. Figure 2 (c) shows the spectrum of incident photon to current conversion efficiencies (IPCE) obtained from the nanocrystalline $\mathrm{TiO}_{2}$ solar cells sensitized by TPTA dye.The IPCE performances were mainly observed in the 400-600 $\mathrm{nm}$ ranges and the photocurrent action spectra resembled well with the absorption spectrum of TPTA, indicating that photocurrent is generated by the electron injection from the excited TPTA molecules into the conduction band of the semiconductor $\mathrm{TiO}_{2}$. Therefore, photon energies in the visible light around 400-600 nm can be converted to current with a maximum of $\sim 30 \%$ around $550 \mathrm{~nm}$, which is better than those of solid organic photovoltaic solar cells and comparable to those of solar cells sensitized with perylene derivatives [7] , merocynanin dyes and pthalocyanine derivatives [15]. Further, the red shift of the action spectra with the optical absorption spectrum is an indication for the chemical attachment of TPTA to the semiconductor.

The dark and the photo current-voltage curves obtained for the cells sensitized with TPTA are shown in the figure 3 . While curve (a) illustrates the dark current behavior of the cell, the curve (b) depicts the photoresponses of the cell under the illumination of $100 \mathrm{~mW} \mathrm{~cm} \mathrm{~cm}^{-2}$ (A.M. 1.5, 1 sun). The average thickness of the $\mathrm{TiO}_{2}$ photoelectrode was $\sim 6.5 \mu \mathrm{m}$. As depicted by the curve (a) it is clear that back current is low, suggesting that the low interfacial recombination of photo injected electrons with the oxidized half of the redox couple $\mathrm{I}^{-} / \mathrm{I}_{3}^{-}$. 


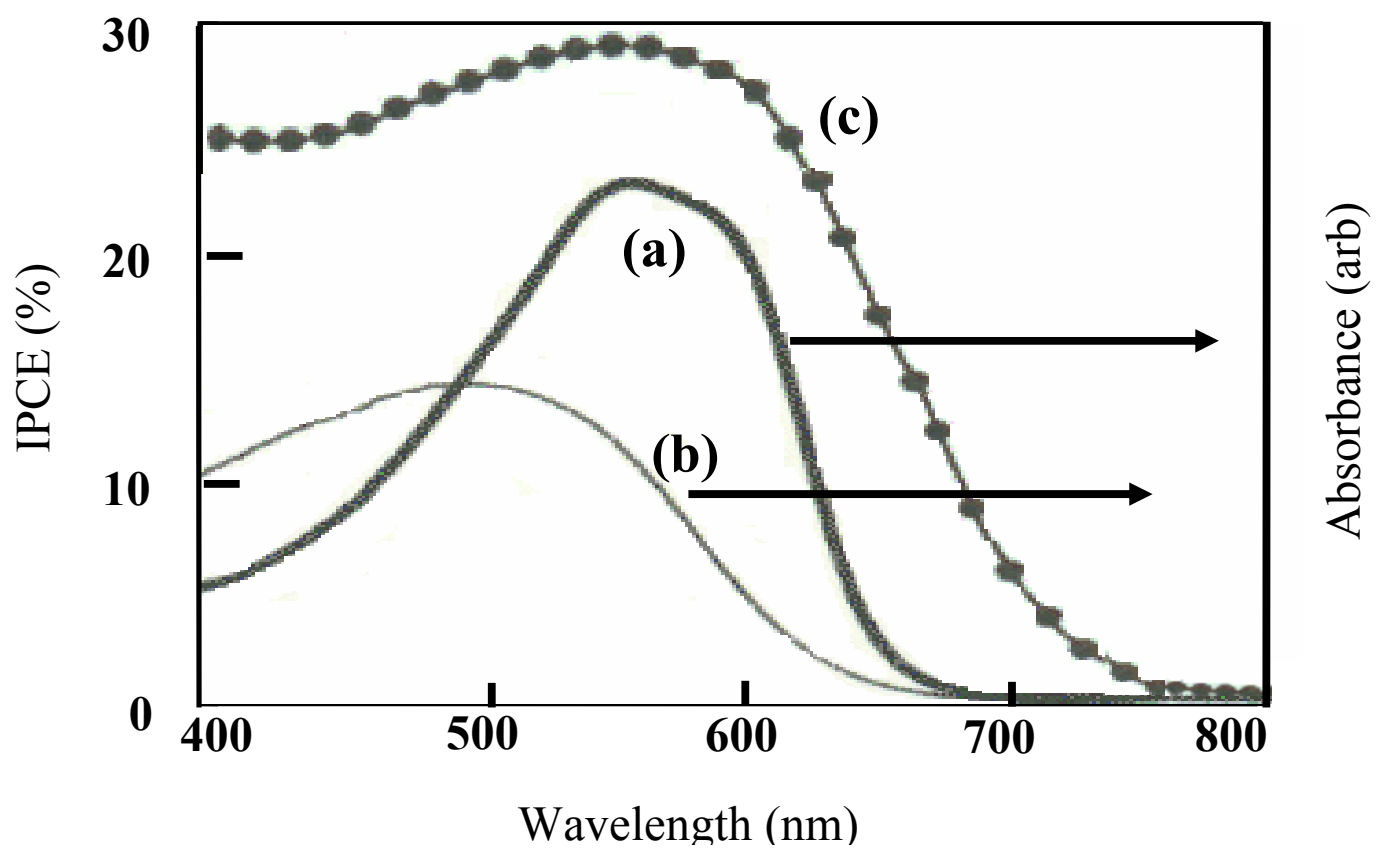

Figure 2: UV-Visible absorption spectrum of TPTA in (a) DMSO and (b) on $\mathrm{TiO}_{2}$ electrode. (c) IPCE spectrum of $\mathrm{TiO}_{2} / \mathrm{TPTA} /$ Electrolyte.

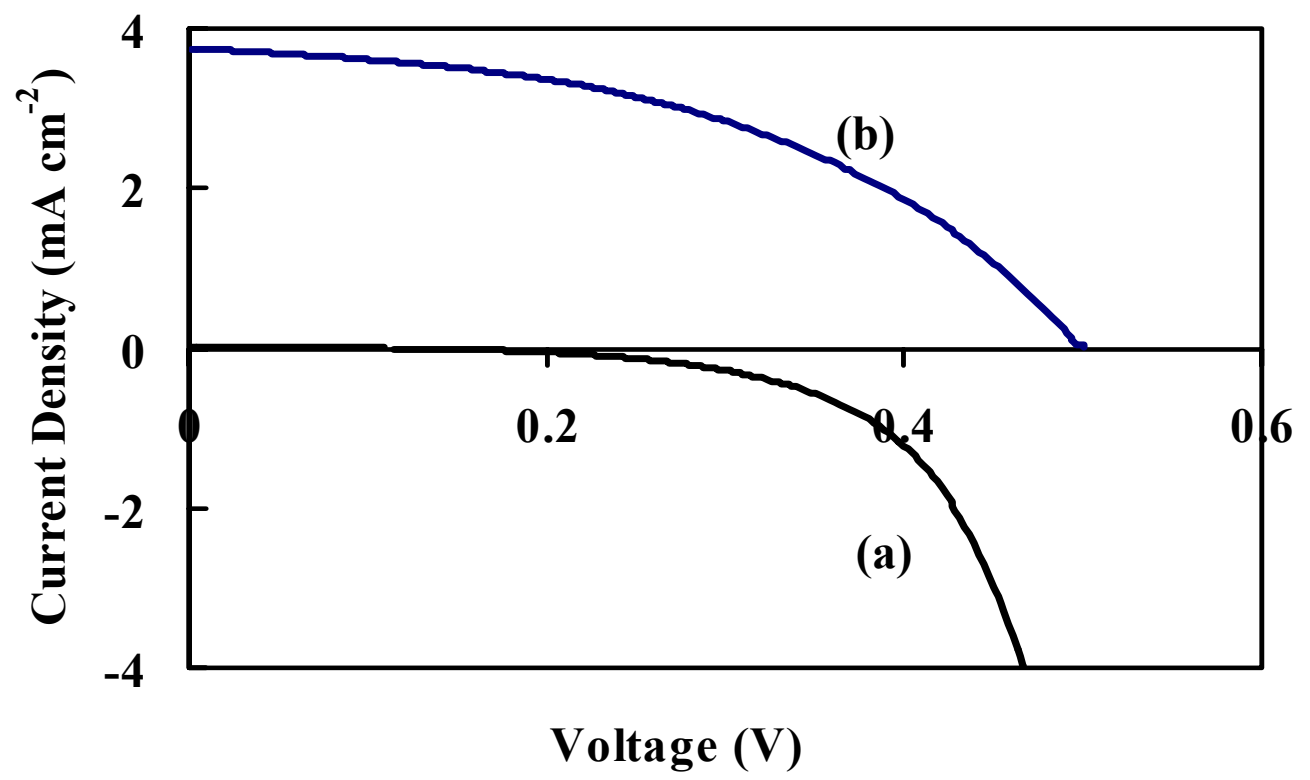

Figure 3: Current-voltage characteristics of the cell $\mathrm{TiO}_{2} / \mathrm{TPTA} /$ Electrolyte under (a) dark and (b) illuminated conditions.

Under the illumination of 1 sun the cell generated $3.5 \mathrm{~mA} \mathrm{~cm} \mathrm{~cm}^{-2}$ of short circuit photocurrent density with, $500 \mathrm{mV}$ of open circuit voltage. The average fill factor and the 
light to electron conversion efficiency of the cell were 0.55 and $\sim 1 \%$ respectively. The stability of the dye was tested with unsealed cell and the results showed that there was a little variation for the performances of the cell under illumination. The long-term stability will be carried out for the sealed cells.

\section{CONCLUSION}

In conclusion, a new triazo dye was synthesized by tri(p-aminophenyl)amine and 2hydroxy-3-napthoic acid and the photo-to-electron properties were studied for the resulting dye sensitized cells for the first time. The results showed that the dye could easily be degraded on $\mathrm{TiO}_{2}$ film under illumination in the absence of donors. However the cell with $\mathrm{I}^{-} / \mathrm{I}_{3}{ }^{-}$electrolyte becomes quiet stable and generated considerable and comparable photocurrent with the previously reported dyes.

\section{REFERENCES}

1. B. O' Regan and M. Grätzel, low-cost, high-efficiency solar cell based on dye-sensitized colloidal TiO2 films, Nature, $\underline{353}$, (1991) 737.

2. Z.-S,.Wang, F.-Y. Li, C.-H. Huang, Photocurrent Enhancement of Hemicyanine Dyes Containing $\mathrm{RSO}_{3}^{-}$Group through Treating $\mathrm{TiO}_{2}$ Films with Hydrochloric Acid. J. Phys. Chem. B. 105 (2001) 9210.

3. S. A. Sapp, C.M. Elliot, C. Contado, S. Caramori and C.a. Bignozzi, Substituted Polypyridine Complexes of Cobalt(II/III) as Efficient Electron-Transfer Mediators in DyeSensitized Solar Cells, Am. Chem. Soc., 124, (2002) 11215.

4. R. Argazzi, C.A. Bignozzi, T.A. Heimer, F.N. Castellano and G.J. Meyer, Light-Induced Charge Separation across $\mathrm{Ru}$ (II)-Modified Nanocrystalline $\mathrm{TiO}_{2}$ Interfaces with Phenothiazine Donors, J. Phys. Chem. B. 101, (1997) 2591.

5. K. Sayama, K. Hara, N. Mori, M. Satsuki, S. Suga, S. Tsukagoshi, Y. Abe, H. Sugihara and H. Arakawa, Photosensitization of a porous $\mathrm{TiO}_{2}$ electrode with merocyanine dyes containing a carboxyl group and a long alkyl chain, Chem. Commun., 13 (2000) 1173. 
6. K. Hara, K. Sayama, Y. Ohga, A. Shinpo, S. Suga and H. Arakawa, A coumarin-derivative dye sensitized nanocrystalline $\mathrm{TiO}_{2}$ solar cell having a high solar-energy conversion efficiency up to 5.6\%, Chem. Commun., $\underline{6}$ (2001) 569.

7. S. Ferrere and B.A. Gregg, New perylenes for dye sensitization of $\mathrm{TiO}_{2}$, New J. Chem., 26 (2002) 1155.

8. K.Y. Law. Organic photoconductive materials: recent trends and developments, Chem. Rev., $\underline{93}$ (1993) 449 .

9. K. Murakoshi, R. Kogure, Y. Yada and S. Yanagida, Fabrication of solid-state dye-sensitized $\mathrm{TiO}_{2}$ solar cells combined with polypyrrole, Solar Energy Mat and Sol cells., 55 (1998) 113.

10. L. Ziolkowski, L, K. Vinodgopal, P.V. Kamat, Photostabilization of Organic Dyes on Poly(styrenesulfonate)-Capped $\mathrm{TiO}_{2}$ Nanoparticles, Langmuir, 13 (1997) 3124.

11. C. Nasr, K. Vinodgopal, L. Fisher, S. Hotchandani, A.K. Chattopadhyaya and P.V. Kamat, Environmental Photochemistry on Semiconductor Surfaces. Visible Light Induced Degradation of a Textile Diazo Dye, Naphthol Blue Black, on $\mathrm{TiO}_{2}$ Nanoparticles, J. Phys. Chem. B., 100, (1996) 8346.

12. N. DiCesare, J.R. Lakowicz, New Color Chemosensors for Monosaccharides Based on Azo Dyes, Org. Lett. $\underline{3}$ (2001) 3891.

13. T. Niimi, M. Umeda, M, Electron Transfer between a Photoexcited Azo Pigment Particle and an Electron Donor Molecule in a Solid System, J. Phys. Chem. B 106 (2002) 3657.

14. X. Tengfeng, W. Dejun, Z. Lianjie, W. Ce, L. Tiejin, Z. Xueqin, W. Mang, Application of Surface Photovoltage Technique to the Determination of Conduction Types of Azo Pigment Films. J. Phys. Chem. B 104 (2000) 8177.

15. H. O. Yadav, T. S. Varadarajan, M. Mohanty, B. N. Pattanaik and L. N. Patnaik, Rise and decay time kinetics of photocurrent in merocyanine dyes, Solar Energy Materials and Solar Cells, $\underline{35}$ (1994) 341 